\title{
FINDING EFFICIENT STRATEGIES IN 3-VERSUS-2 SMALL- SIDED GAMES OF YOUTH SOCCER PLAYERS
}

\author{
Roland Leser', Thomas Hoch², Xiaoying Tan², Bernhard Moser², \\ Gernot Kellermayr ${ }^{3}$, and Arnold Baca ${ }^{1}$ \\ ${ }^{1}$ Centre of Sport Science and University Sports, University of Vienna, Vienna, Austria \\ ${ }^{2}$ Software Competence Center Hagenberg GmbH, Hagenberg, Austria \\ ${ }^{3}$ Inmotiotec GmbH, Oberregauer Straße, Regau, Austria
}

Original scientific paper

https://doi.org/10.26582/k.51.1.7

\begin{abstract}
:
Most existing game analysis attempts do not consider situational context information sufficiently for the assessments of tactical behaviour. The purpose of this case study was to apply a new analysis approach, so far only used for 1-versus-1 analyses in soccer, to small-sided games and to identify and analyse therewith the efficiency of tactical patterns in 3-versus-2 game play. Therefore, 279 games, performed by an elite youth soccer team, were recorded by video and a position tracking system. The data was processed by the new approach, including unsupervised machine learning routines and artificial intelligence methods. Two crucial moments were used to analyse the occurring tactical patterns for the specific game: T0 (time instant of the shot) and T1 (time instant of the last action before the shot). For both moments typical tactical patterns, considering the spatio-temporal context of the situations, were found. By combining the patterns of both moments, hidden tactical strategies were identified and their efficiencies calculated. The most significant result is that offence attempts have the highest scoring probability when played via the wings near to the goal line and the final pass, before the shot, is given against the playing direction into the centre of the field.
\end{abstract}

Key words: soccer, tactical behavior, assessment, performance analysis, small-sided game

\section{Introduction}

In recent years, small-sided games (SSGs) in soccer have become an important subject to sport science because they are more and more used as a training regime to improve physical capacities as well as technical and tactical skills (Reilly, 2005). Moreover, by performing SSGs, players experience similar situations to those they are exposed in eleven-a-side competitive matches (Owen, Twist, $\&$ Ford, 2004). The mutual development of perceptual, cognitive and motor skills is in particular important in young years (Proteau, Marteniuk, \& Le'vesque, 1992). However, by now a majority of the SSG studies focused mainly on their physical and physiological effects in youth soccer (e.g., Brandes, Heitmann, \& Müller, 2012; Casamichana, \& Castellano, 2010; Dellal, et al., 2011; Hill-Haas, Coutts, Rowsell, \& Dawson, 2008; Jones \& Drust, 2008; Katis \& Kellis, 2009). Only few studies investigated individual players' and collective behaviours, which determine strategic and tactical aspects in game play (Almeida, Ferreira, \& Volossovitch,
2013; Barnablè, Volossovitch, Duarte, Ferreira, \& Davids, 2016; Serra-Olivares, Clemente, \& Gonzàlez-Villora, 2016).

Game or playing strategies are coaches' plans for how their teams or individual players ought to act during matches and in specific game situations. The execution of these plans, however, does not always go along with the ideas of the coaches. Nevertheless, the players' actions on the field can be observed as tactical behaviour. Good tactical behaviour in game sports is associated with doing the right actions at the right moment (Kannekens, Elferink-Gemser, \& Visscher, 2011) and is always goal-oriented. This means that tactical actions always pursue certain purposes. Generally, attacking teams in soccer try to score goals, whereas defending teams try not to concede a goal and to interfere with the attack of the opponent team. All tactical activities aim to attain those goals or subgoals thereof - like bringing the ball into the next field zone (attacker's viewpoint) or preventing the attacker to overcome an opponent (defender's viewpoint). 
The assessment of such tactical behaviour, in particular of individual game actions, is a recent study object of high interest (Gonzalez-Villora, GarciaLopez, \& Contreras-Jordan, 2015; Memmert, 2010; Otero-Saborido, \& Gonzalez-Jurado, 2015) and is also relevant for player evaluations in the practice (e.g., for player recruitments). Gonzalez-Villora et al. (2015) found six tools, which met the requirements of both fields, research and practice, respectively: the Game Performance Assessment Instrument (Oslin, Mitchell, \& Griffin, 1998), the Performance Assessment in Team Sports (Grehaigne, Godbout, \& Bouthier, 1997), the Procedural Tactical Knowledge Test (Memmert, 2002), the Game Performance Evaluation Tool (Garcia-Lopez, Gonzalez-Víllora, Gutierrez-Diaz, \& Serra-Olivares, 2013), the System of Tactical Assessment in Soccer (Costa, Garganta, Greco, Mesquita, \& Maia, 2011) and the method of conventional game performance analysis (Hughes \& Franks, 2004). Summarised, all six tools register the occurrences of observable player actions, which are related to basic game principles of invasion games, and evaluate these events by calculating frequencies, performance indicators or specific indices. A main drawback of these tools is the dependency on human observation, which is very time consuming and limited to specific observation tasks.

The quality of a player's individual tactical behaviour is related to his/her contribution to the team's goals and subgoals accomplishment. Thus, evaluations of individual peformances have to consider relevant collective patterns that determine the framework of players' actions during a game (Clemente, Martins, Mendes, \& Figueiredo, 2014). Observable collective game patterns, understood as team strategies (Taylor, Mellalieu, \& James, 2005), strongly depend on contextual variables. Game context is an intensively investigated subject: Pollard and Pollard (2005), for instance, investigated variables influencing home advantage in football. Sampaio, Lago, Goncalves, Macas, and Leite (2013) compared tactical behaviours according to game pace, game status and team unbalance. Silva et al. (2014) investigated how different field dimensions and skill levels constrained tactical behaviours. All these studies explore (general) context information on a macro-level, considering the effect of contextual variables on a couple of games or events. For tactical decision-making in specific game moments the situational context is even more important. This situational context covers besides general context information and other relevant factors (e.g., team strength, current score) in particular variables that are very specific for the analysed game situation like the players' role, positioning, kinematic variables or interactions. Additionally, tactical behaviour often changes from game moment to game moment, depending on the proceeding of events and interactions. Therefore, also the processual character of game situations should be considered in tactical analyses.

In a cognitive perspective, tactical behaviour can be understood as the solution for a given problem in a game-related situation. This solution is commonly measured by the analysis of "What did the players do?" in each situation by observation. This is often a more qualitative than a quantitative approach. On a macro-level (when the game is observed from a bird's-eye view) this "decisionmaking" skills (being the basis of tactical behaviour in a cognitive perspective) can be assessed by means of the movements of the objects (players and the ball). Therefore, the most powerful way to quantitatively describe the players' behaviour in a holistic way and within the situational context during spatio-temporal processes in game sports is currently provided by tracking systems. Tracking systems supply position data of all players and the ball for each single moment of the game (Leser, Baca, \& Ogris, 2011). Since contemporary systems calculate the position data very precisely and operate semiautomatically or even automatically (Leser \& Römer, 2014), the precondition for the computerised and automatised tactics analysis in game sports is given. Thus, contemporary game analysis, based on automatically collected position data of all players for the whole game, pursues the automation of event detection and behavioural assessments.

State-of-the-art analysis approaches use position data to investigate complex and non-linear properties of sport games. Sampaio and Macas (2012), for instance, analysed the inter-player coordination by means of collective variables like the team centroid, stretch index and surface area. Lemmink and Frencken (2013) measured, by means of similar variables, the inter-team and inter-line coordination before critical events. Perl, Grunz, and Memmert (2013) used artificial neural networks to perform pattern analysis, which resulted in measures for team compactness and inter-team interactions.

All these novel approaches analyse collective behavioural patterns from a rather basic science viewpoint, whereas this paper tries to bridge the gap to applied science. Therefore, we operationalise the available data for performance analysis also by means of qualitative methods and expert experiences. Therewith valuable evidence-based expert knowledge can be used to develop performance analysis models with high ecological validity. This proceeding might also raise the acceptance of practitioners towards scientific results and help to close the existing gap between science and practice (Mackenzie \& Cushion, 2013).

Leser et al. (2015) analysed behaviour of two soccer players (an attacker and a defender) in a 1-versus-1 situation by means of position data, using 
expert knowledge for the underlying kinematic model. However, the players' tactical behaviour was only evaluated by means of isolated performance indicators, such as distances, speeds and accelerations at specific moments. The authors concluded that expert-based descriptions of tactical actions by means of tracking data considering contextual information and multiple interactions inevitably led to very complex analysis tasks, which could not be solved by one-dimensional statistical tests. For this purpose measures are required that consider the multi-dimensional framework of the game or testing situation. Therefore, Hoch, Tan, Leser, Baca, and Moser (2017) developed a more sophisticated approach, using data mining methods, to fix these problems. Additionally, they fuzzified the spatio-temporal input variables (e.g., concrete speed values are assigned to fuzzy terms like "slow" and "fast") in order to provide the user of the system (e.g., a coach) with an understandable and reasonable output. The aim of the current study was to apply this approach to a more complex game-like situation and to analyse therewith the efficiency of specific tactical patterns in a selected small-sided game. The applied approach meets the requirement for the analysis of goal-oriented tactical behaviour, considers not only observable ball actions but all crucial actions within its situational context, claims high ecological validity, and pursues a fully automated process.

\section{Methods}

\section{Participants and sample}

In this study 20 soccer players of a youth academy team (age: $15.1 \pm 0.34$ years, body height: $176.2 \pm 6.34 \mathrm{~cm}$, body mass: $64.4 \pm 6.14 \mathrm{~kg}$ ) participated in 279 three-versus-two small-sided games (3-vs-2 SSGs).

The proceeding of the 3-vs-2 SSGs is illustrated in Figure 1. The games were played on a field twice the penalty area size $(40.32 \times 33.00 \mathrm{~m})$. The start of each game was standardised in order to make the initial contextual situation of all executions more comparable. Each game began with a pass of an attacking player, starting at the left post, to a team-mate waiting left-outside at the midfield line. The third attacker started at the right post. The two defenders were positioned in their own half, supported by a goalkeeper allowed to make all regular movements. The aim of the attacking team was to score a goal, while the defending team tried to prevent this or even to win the ball. A game was finished by the attackers' goal scoring, ball loss through a turnover, or when the ball left the playing field. In addition to this, the normal rules of the game (including offside) were applied. After a bout, all players, except the goalkeeper, left the field and other five field players started a new bout. Due to the switch after each bout, the teams always had different personnel constellations. The goalkeeper was the main keeper of the team and participated in all bouts.

A main reason for choosing this special type of a 3-vs-2 regime was that this game is the most frequently used in Austrian academy soccer besides 5-vs-5 SSGs. The proceeding, as explained above, ensures 3-vs-3 situations (three attackers versus two field defenders and their goalkeeper), when it comes to complete an attack. Costa et al. (2011) stated that 3-vs-3 SSGs embraced all the most relevant requirements of formal game play. Brandes et al. (2012) have concluded that three-a-side formats, with a similar grid ratio per player, like used in our study, reveal game-like physiological responses and therefore are well suited to increase soccer-specific aerobic fitness. Similar, Katis and Kellis (2009) have recommended 3-vs-3 formats to improve physical condition but also technical skills of young soccer players.

The games were performed in 12 different training sessions (four consecutive weeks; three sessions per week; 20 to 25 bouts per session) with similar weather conditions (dry weather, temperatures between 15 and 25 degrees Celsius), immediately after a standard warm-up (twelve minutes of
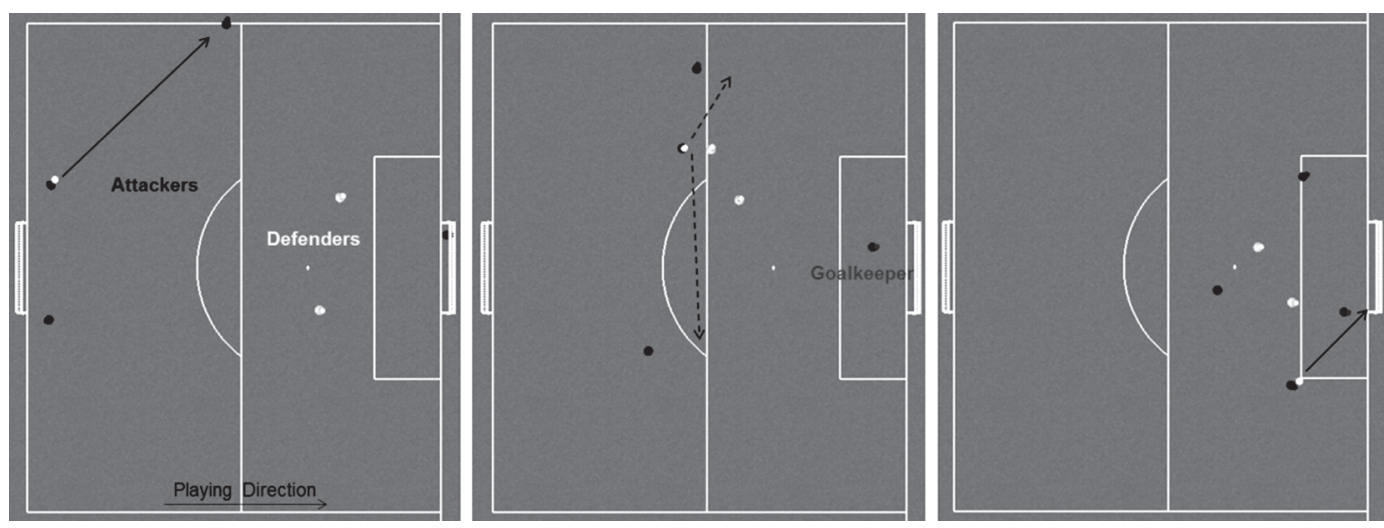

Figure 1. Proceeding of the 3-vs-2 SSG with the starting point (left), passing options during the game (middle) and shooting situation (right). 
low-intensity activities, followed by three minutes of active recovery).

The execution format of the games was explained before each session by the coaches, who were initially informed by the researchers. There was no audience and during the games there were no instructions or feedbacks neither by the coaches nor by the researchers.

The players performing the exercise were tracked by the Inmotiotec local position tracking system. This system uses radio waves to detect transponders worn by the players in a special belt on their shoulders. Current studies attest sufficient accuracy for the study's belongings (Ogris, et al., 2012; Stevens, et al., 2014). Besides position data, the system also provided distances, speeds and accelerations of the players for each time instant. The measurement rate was $50 \mathrm{~Hz}$ for each player. Furthermore, all games were recorded with a digital camcorder for the human post-game observation.

All players involved in the study read and signed a consent form, which was approved by the Ethics Committee of the University of Vienna.

\section{Data processing}

The data was processed according to the approach explained by Hoch et al. (2017) and as outlined in Figure 2. Based on the expert knowledge gathered by interviews (Leser, et al., 2015) the 3-vs-2 SSG was temporally segmented into a sequence of phases defined by certain events (e.g., shot, pass). In order to reduce complexity the time instant of the shot taken $\left(\mathrm{T}_{0}\right)$ and the time instant of the last action before the shot $\left(T_{1}\right)$ were defined as the most crucial moments determining the outcome of a 3-vs-2 game by an expert panel. All in all, 30 kinematic parameters (e.g., distances between players, movement speeds, accelerations), which were determined as relevant by experts, were calculated for these time instants and phases (for more details regarding the selection of experts and parameters, see Leser, et al., 2015). The statistical analysis comprised methods for feature reduction and pattern recognition. Using the Laplacian Score (He, Cai, \& Niyogi, 2005), the kinematic parameters were reduced to a manageable number of features, which were still representative for the whole parameter space (see the Results section for the list of parameters). Based on this small number of features, spectral clustering ( $\mathrm{Ng}$, Jordan, \& Weiss, 2002), an unsupervised data mining method, was applied to find hidden patterns in the data (for more details regarding the applied machine learning methods, see Hoch, et al., 2017). These patterns can be interpreted as typical recurring prototypes of tactical behaviour and represent team strategies in the context of coaching.

For all the measured games the outcome (turnover, shot taken or goal scored) was recorded. Therewith, for each pattern/tactical strategy the success rate was calculated by means of the goal ratio.

\section{Results}

The automatic feature reduction resulted in four parameters for $\mathrm{T}_{0}$ (distance between the shooter and the opponent goalkeeper; distance between the shooter and the next opponent defender; angle between the lines from the shooter to the left and to the right goal posts; angle between the goal line and the line between the shooter and the centre of the goal), and in three parameters for $\mathrm{T}_{1}$ (distance between the passer and the next opponent defender; length of the pass in the longitudinal direction of the field; length of the pass in the transversal direction of the field).

Out of the 279 analysed bouts, $220(79 \%)$ resulted in a shot taken, $60(22 \%)$ of which ended successfully with a goal scored, whereas 160 shots

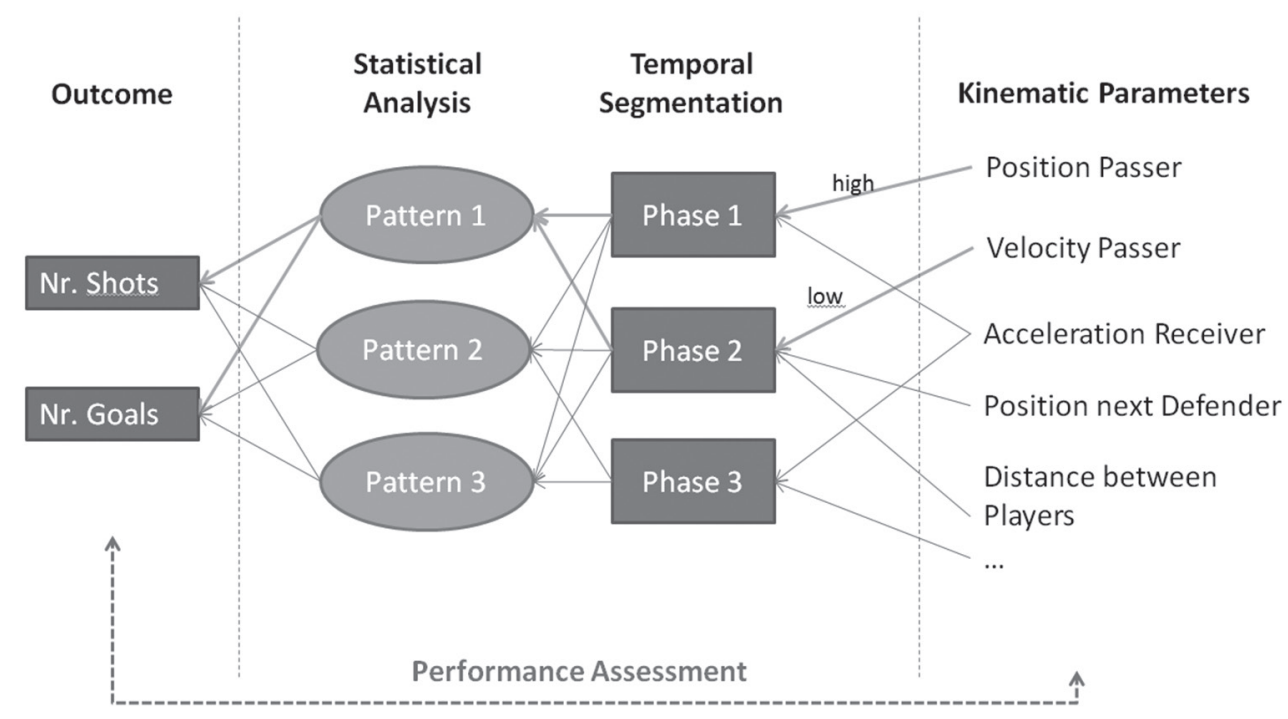

Figure 2. Basic analysis approach (Hoch, et al., 2017). 
(57\%) were either saved, blocked, or off target. In $57(20 \%)$ of the bouts the ball was turned over to the defenders and 2 attacks (1\%) ended with a foul. All the 220 bouts completed by a shot were used to perform pattern recognition for each of the two key moments by means of the five selected features, which revealed the following results:

\section{Pattern recognition $T_{0}$}

For the time instant of the shot three prototypes of tactical constellations (shot patterns $\mathrm{T}_{0}-\mathrm{I}, \mathrm{T}_{0}$-II and $\mathrm{T}_{0}$-III) were found (Figure 3 ). The $\mathrm{T}_{0}$-II pattern covers central shots taken from a small to middle distance to the goal with a goal ratio of $29.1 \%$. The $\mathrm{T}_{0}$-I pattern has nearly the same goal ratio $(28.9 \%)$. It represents short-distance shots from slightly lateral positions, but - different from the $\mathrm{T}_{0}-\mathrm{II}$ pattern - with defenders not directly covering the line of shot. The $\mathrm{T}_{0}$-III pattern shots are taken from large distances from central or lateral positions. Its goal ratio is only $19.5 \%$ on average.

\section{Pattern recognition $T_{1}$}

The pattern detection for the last game situation before the shot taken resulted in four typical prototypes. The first pattern $\left(\mathrm{T}_{1}-\mathrm{D}\right)$ covers all situations where the ball is dribbled by the shooter to the position of the shot (goal ratio $=23.0 \%$ ), the other three patterns (patterns $\mathrm{T}_{1}-\mathrm{I}, \mathrm{T}_{1}$-II and $\mathrm{T}_{1}$-III; Figure 4) are pass actions. The $\mathrm{T}_{1}$-II pattern contains passes from the central lane to the side with a goal ratio of $25.9 \%$. Almost the same goal ratio has the $\mathrm{T}_{1}-\mathrm{I}$ pass pattern (25.8\%). It covers cross-field passes all over the field. The $\mathrm{T}_{1}$-III pattern is the assist type with the much higher goal ratio (50.0\%). It represents backward passes from the side to the center.

\section{Pattern merging}

The most powerful output of the analysis can be generated by combining the results of the pattern recognition at $\mathrm{T}_{0}$ and $\mathrm{T}_{1}$. Table 1 contains the absolute numbers of all observed transitions between the found patterns and their goal rates. Not considering

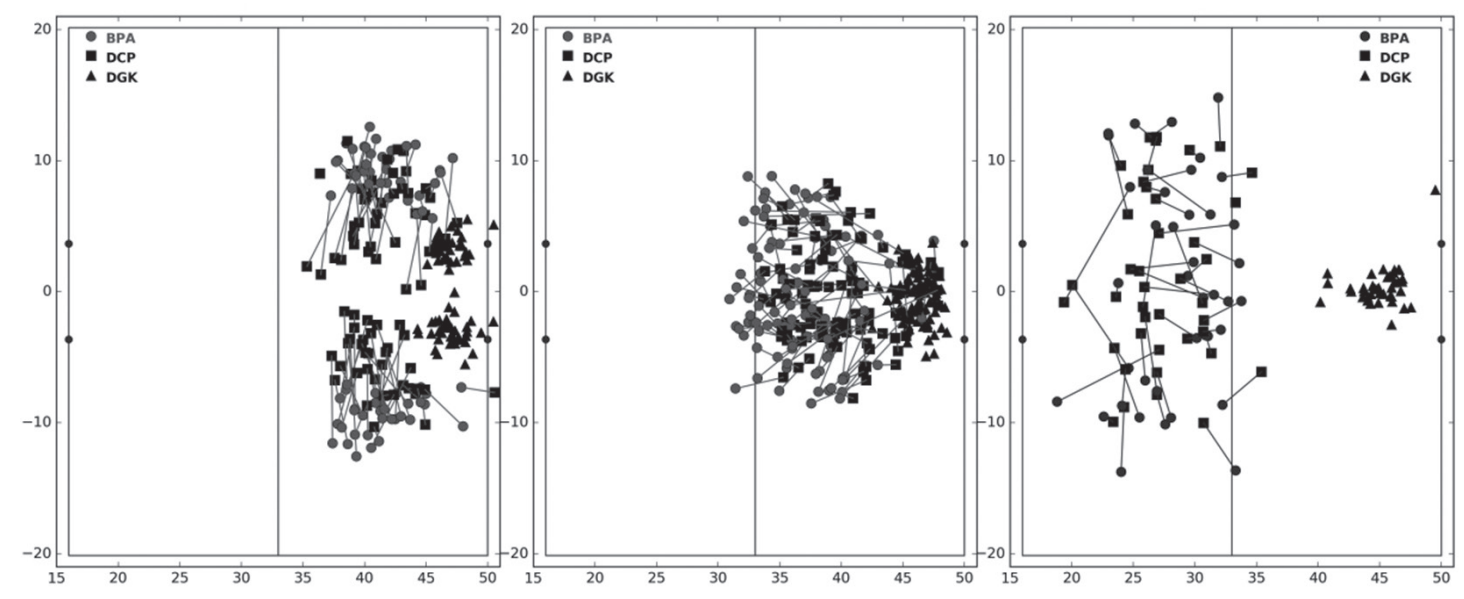

Figure 3. The three tactical patterns at $T_{0}$ showing the playing field with the goals and positions of the attacker in ball possession (BPA), of the defender next/close to the ball possessor (DCP) and of the defender's goalkeeper (DGK). The goal ratios are $28.9 \%$ for cluster $T_{0^{-}}$I (left), 29.1\% for cluster $T_{0}$-II (middle) and 19.5\% for cluster $T_{0}$-III (right); playing direction is from left to right.

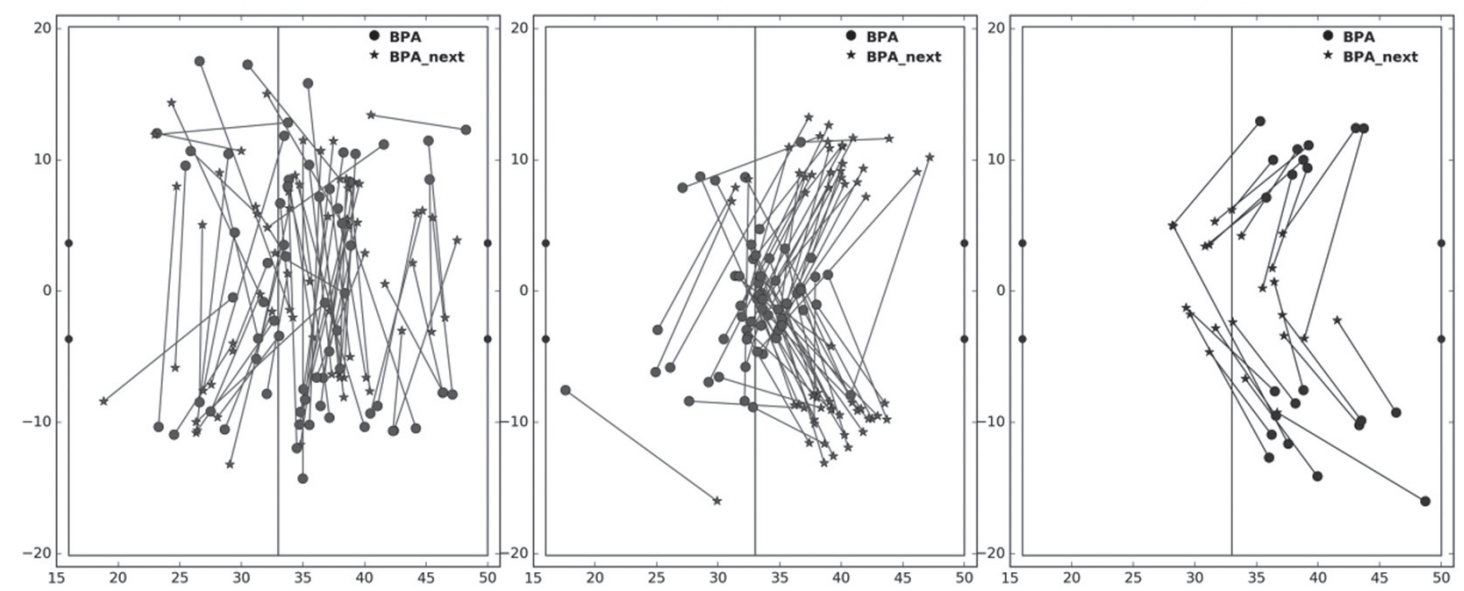

Figure 4. The three tactical patterns at $T_{1}$ showing the playing field with the goals and positions of the attacker in ball possession (BPA=passer) and of the attacker in ball possession after the pass (BPA_next=receiver). The goal ratios are 25.8\% for cluster $T_{I}$-I (left), $25.9 \%$ for cluster $T_{1}$-II (middle) and $50.0 \%$ for cluster $T_{I^{-}}$III (right); playing direction is from left to right. The dribbling pattern T1-D (goal ratio $=23.0 \%$ ) is not shown here. 
the very rare transition from the $\mathrm{T}_{1}$-III pattern to the $\mathrm{T}_{0}$-III pattern (one occurrence), nearly all transition types have very homogenous goal ratios - between 22 and $30 \%$, but with three exceptions: the dribbling pattern $\left(\mathrm{T}_{1}-\mathrm{D}\right)$ to the $\mathrm{T}_{0}$-III pattern transition with of $11 \%$ goal ratio only; the transition from the dribbling to the $\mathrm{T}_{0}$-I shooting pattern with a goal rate of $40 \%$; and the sequence $\mathrm{T}_{1}$-III to $\mathrm{T}_{0}$-II with the highest goal ratio of all transitions (48\%).

Table 1. Absolute numbers of transitions between the T1 patterns and T0 patterns and goal scoring propabilities (in brackets)

\begin{tabular}{lccc}
\hline & $\mathrm{T}_{0}-\mathrm{I}$ & $\mathrm{T}_{0}-\mathrm{II}$ & $\mathrm{T}_{0}-$ III \\
\hline $\mathrm{T}_{1}-\mathrm{D}$ & $15(40 \%)$ & $41(22 \%)$ & $18(11 \%)$ \\
$\mathrm{T}_{1}-\mathrm{I}$ & $10(30 \%)$ & $34(26 \%)$ & $22(23 \%)$ \\
$\mathrm{T}_{1}-\mathrm{II}$ & $51(25 \%)$ & $7(29 \%)$ & 0 \\
$\mathrm{~T}_{1}-\mathrm{III}$ & 0 & $21(48 \%)$ & $1(100 \%)$ \\
\hline
\end{tabular}

\section{Discussion and conclusions}

Due to a high complexity and countless number of different situations occurring in invasion games like soccer, the analysis of tactical behaviour in these sports is very challenging.

The aim of this study was to apply an approach based on tracking data and data mining methods developed by the authors for the assessment of tactical behaviour in soccer with the aim to analyse therewith efficiency of tactical strategies in a specific type of SSG. The usefulness of the approach can be discussed based on the obtained results. Our methodology (1) takes into account expert knowledge for modelling the assessment system; (2) uses positional data of all players to incorporate the most crucial context information, in particular off-ball actions, player interactions and the processual property of game situations; (3) decreases complexity of the data space by proper methods of parameter reduction; (4) searches for hidden patterns in the available data by data mining methods; (5) clusters similar game settings to one type of a situation; (6) works goal-oriented by evaluating team and player behaviour based on its outcome (quantified by goal ratios); (7) considers individual behaviour as a contribution to collective performance; and (8) is already approved for assessing players's tactical behaviour in low complex SSGs (Hoch, et al., 2017). The developed assessment tool was applied to a 3 -vs-2 testing situation. Though this type of a SSG is by far not as complex as the eleven-aside game, it is more game-like than the approved testing situation in Hoch et al. (2017) and also shares some crucial properties with the full-sided game. The 3-vs-2 SSG testing form was chosen to increase the contextual complexity conferred to the 1-vs-1 situation and to control the degrees of freedom, which is not possible for free play. In the 3-vs-2 SSG the attacking team has numerical superiority at the start (Figure 1). This counter-attack-like situation fosters the ball possessing team to play their attack straight forward and thus reduces the degrees of freedom in the game proceeding. However, by the attackers' approach to the opponents' goal, the numerical situation changes from 3-vs-2 into 3 -vs-3 due to the goalkeepers's rather active defending role. Costa et al. (2011) reason that the 3-vs-3 SSG ensures the occurrence of all tactical principles inherent to formal play for the offensive team as well as for the defensive team.

The applied analysis approach is intended to be used also by practitioners like coaches or performance analysts in clubs. Therefore, a high number of the observed parameters was reduced to only five variables, which enabled us to describe the resulting tactical patterns sufficiently. The used variables are reasonable, manageable in their number and interpretable for the soccer expert. Additionally, the processed kinematic data as well as the results are expressed in fuzzy terms (Hoch, et al., 2017) which are based on the coaching language (e.g., "short distance", "long pass", etc.).

The results of the 3-vs-2 SSG analysis unveil that the final shooting situation is approximately twice as often created by a pass (assist) than by a dribbling of the shooter and that the shots after passes are much more successful than those after dribblings. This comes along with the fundamental tactical principles of football (Clemente, et al., 2014). The dribblers are most often under higher pressure of the opponent than the pass receivers; therefore, the shots of the receivers are more efficient than those of dribblers. Exceptions are duels, where dribblers may overrun the defenders thus opening nearly free line to the goal. This is supported by the high goal rate $(40 \%)$ for the transition from the dribbling $\mathrm{T}_{1}$ pattern to the $\mathrm{T}_{0}$-I pattern, whereas the $22 \%$ and $11 \%$ goal rate from $\mathrm{T}_{1}-\mathrm{D}$ to the two other shooting patterns are below-average.

Furthermore, the results give evidence to some state-of-the-art knowledge in training science and practice regarding the preparation of shooting situations. Passing, dribbling and shooting actions should always pursue to gain an advantage for the attacking team. There are two main relevant factors for having advantage in the 3-vs-2 SSG - positioning and pressure. The study's results confirm that long shots are not as promising as shots from middle or short distances. Generally, shots from the center of the field have higher scoring probabilities than side shots, but at this there is a strong relation to the factor pressure. If the ball carrier passes past a defender and in this way moves from the center to the side, but at the same time he has less pressure by his opponent, then the scoring probability even so might increase. 
Summarised, getting good goal scoring opportunities in 3-vs-2 SSGs is all about preparing attacks to get the shooter in the situations where he/she has a good scoring position and less pressure. At this, the most considerable result regarding the pass-shot transitions is the $48 \%$ goal ratio for the $\mathrm{T}_{1}$-III pattern to the $\mathrm{T}_{0}$-II pattern, which was detected to be the most efficient way to score a goal in the 3-vs-2 SSG. On the one hand, this finding supports basic tactical rules of soccer like the offensive "Width and Length Principle" or the defensive "Concentration Principle" (Clemente, et al., 2014); on the other hand, it gives some new insights into tactical interactions in soccer. While the established training theories teach the team in ball possession to position players so to cover as much space as possible, our study alo reveals some crucial information about the course and direction of passes. If a player has the ball on the wing and near the goal line, the defenders shift to this side and move into the direction of the goal. This creates space for attackers moving up in the back of the defenders. If then the so called through-ball (pass through the defence line) is played backwards (reverse to the running direction of the attacking team), an attacker in the center usually has a very promising shooting position, because the goal is immediately in front of him/her and the defenders move away from him/ her (low pressure).

Above all, the current findings regarding game complexity could be masked by the age, respectively experience, of the players. However, we do not know so far if the results are generalisable. There are a couple of studies, which observed experience to be an important factor to influence game style and performance (Ford \& Williams, 2012; Ward \& Williams, 2003; Williams \& Hodges, 2005). Almeida et al. (2013) concluded that experienced players adopted a "possession play" style in 3-vs-2 SSGs, while novice players preferred a more direct style with predominately individual players' actions. However, Almeida et al. (2013) state furthermore that it does not require long periods of deliberate practice in order to observe those differences between the experienced and non-experienced players. The subject players in our study are already well-experienced despite their age. This might give a reason to conclude that the found patterns have generalisable validity.

A further limitation of the study at hand is that all measurements have been made within only one academy team. The tactical behaviour observed might be specific for that special team - probably based on individual abilities or the team training. Therefore, it may be questionable whether the method has identified tactical patterns that are typical for other soccer teams. To weaken these restrictions, our experimental design created a high variability in the personnel team-constellations during the training sessions and bout by bout, respectively. Furthermore, test measurements of the applied SSG in other academy teams revealed similar result tendencies. Moreover, our current investigations in 5 -vs-5 game play indicate that the found patterns are also relevant in more complex SSGs. Subsequently, we will apply our approach up to the eleven-a-side game.

The method proposed in this article detects and evaluates collective attacking patterns in SSGs. This allows to unveil team strategies and to assess team tactical behaviour. Extending our analyses enables to assess the performances of individual players by considering their participation in the observed attacks. Therefore, we calculate the proportion of a player's attacks belonging to the detected attacking patterns. Since we know the goal probability for each of these patterns (see Results section), we can calculate the expected goal ratio for the player based on his/her tactical behaviour. If we divide this value by the average goal ratio of all players and multiply the outcome by 100 , we get the player's percental deviation from the mean performance of all players (values $<100$ indicate under-performance, values $>100$ indicate over-performance).

One main advantage of this method is that players' performances can objectively be assessed even with only few data available. Another advantage is that a player's actual goal ratio can meaningfully be compared with his/her expected goal ratio if extensive data is available. Big differences between the two values go along with unusual behaviour. Lower values for the observed performance indicate weaknesses in the finalisation of attacks and thus reveal players' inefficiency. Higher values for the observed performance can be hints for tactical creativity, because the player's higher output may belong to surprising, original and flexible individual actions within the usual collective patterns (Memmert \& Roth, 2007).

Future research will focus on the assessment of individual players' performances and on the recognition of creativity by applying our approach in further studies.

In game analysis, a strong trend towards the automatization of data processing and data evaluation can be observed. While there already exist a couple of analysis tools and systems that automatically analyse physical data, the number of approaches for the machine-based analyses of tactics in game sports (Memmert, Lemming, \& Sampaio, 2017), like our method presented in this article, is very limited. 


\section{References}

Almeida, C.H., Ferreira, A.P., \& Volossovitch, A. (2013). Offensive sequences in youth soccer: Effects of experience and small-sided games. Journal of Human Kinetics, 36(1), 97-106.

Barnablè, L., Volossovitch, A., Duarte, R., Ferreira, A., \& Davids, K. (2016). Age-related effects of practice experience on collective behaviours of football players in small-sided games. Human Movement Science, 48, 74-81.

Brandes, M., Heitmann, A, \& Müller, L. (2012). Physical responses of different small-sided game formats in elite youth soccer players. Journal of Strength and Conditioning Research, 26(5), 1353-1360.

Casamichana, D., \& Castellano, J. (2010). Time-motion, heart rate, perceptual and motor behaviour demands in smallsides soccer games: Effects of pitch size. Journal of Sports Sciences, 28(14), 1615-1623.

Clemente, F., Martins, F., Mendes, R., \& Figueiredo, A. (2014). A systematic overview of football game: The principles behind the game. Journal of Human Sport and Exercise, 9(2), 656-667.

Costa, I., Garganta, J., Greco, P., Mesquita, I., \& Maia, J. (2011). System of tactical assessment in soccer (FUT-SAT): Development and preliminary validation. Motricidade, 7(1), 69-84.

Dellal, A., Chamari, K., Owen, A.L., Wong, D.P., Lago-Penas, C., \& Hill-Haas, S. (2011). Influence of technical instructions on the physiological and physical demands of small-sided soccer games. European Journal of Sport Science, 11(5), 341-346.

Ford, P., \& Williams, A.M. (2012). The developmental activities engaged in by elite youth soccer players who progressed to professional status compared to those who did not. Psychology of Sport and Exercise, 13(3), 349-352.

Garcia-Lopez, L., Gonzalez-Víllora, S., Gutierrez-Diaz, D., \& Serra-Olivares, J. (2013). Development and validation of the game performance evaluation tool (GPET) in soccer. Revista Euroamericana de Ciencias del Deporte 2(1), 89-99.

Gonzalez-Víllora, S., García-Lopez L., \& Contreras-Jordan, O. (2015). Decision making and skill development in youth football players. Revista Internacional de Medicina y Ciencias de la Actividad Fisica y del Deporte, 59(15), 467-487.

Grehaigne, J., Godbout, P., \& Bouthier, D. (1997). Performance assessment in team sports. Journal of Teaching in Physical Education, 16(4), 500-516.

He, X., Cai, D., \& Niyogi, P. (2005). Laplacian score for feature selection. In Y. Weiss, P. Schölkopf \& J. Platt (Eds.), Advances in neural information processing systems 18 (pp. 507-514). Proceedings of the Neural Information Processing Systems Conference.

Hill-Haas, S., Coutts, A., Rowsell, G., \& Dawson, B. (2008). Variability of acute physiological responses and performance profiles of youth soccer players in small-sided games. Journal of Science and Medicine in Sport, 11(5), 487-490.

Hoch, T., Tan, X., Leser, R., Baca, A., \& Moser, B. (2017). A knowledge discovery framework for the assessment of tactical behaviour in soccer based on spatiotemporal data. Mathematical and Computer Modelling of Dynamical Systems, 23(4), 384-398.

Hughes, M., \& Franks, I. (2004). Notational analysis of sport: Systems for better coaching and performance in sport. New York: Psychology Press.

Jones, S., \& Drust, B. (2008). Physiological and technical demands of $4 \mathrm{v} 4$ and $8 \mathrm{v} 8$ games in elite youth soccer players. Kinesiology, 39(2), 150-156.

Kannekens, R., Elferink-Gemser, M., \& Visscher, C. (2011). Positioning and deciding: Key factors for talent development in soccer. Scandinavian Journal of Medicine and Science in Sports, 21(6), 846-852.

Katis, A., \& Kellis, E. (2009). Effects of small-sided games on physical conditioning and performance in young soccer players. Journal of Sports Science and Medicine, 8(3), 374-380.

Lemmink, K., \& Frencken, W. (2013). Tactical performance analysis in invasion games: Perspectives from a dynamical system approach with examples from soccer. In T. McGarry, P. O’Donoghue \& J. Sampaio (Eds.), Handbook of sports performance analysis (pp. 89-100). London: Routledge.

Leser, R., Baca, A., \& Ogris, G. (2011). Local Positioning Systems in (game) sports. Sensors, 11(19), 9778-9797.

Leser, R., Moser, B., Hoch, T., Stögerer, J., Kellermayr, G., Reinsch, S., \& Baca, A. (2015). Expert-oriented modelling of a 1vs1-situation in football. International Journal of Performance Analysis in Sport, 15(2), 949-966.

Leser, R., \& Roemer, K. (2014). Motion tracking and analysis systems. In A. Baca (Ed.), Computer science in sport: Research and practice (pp. 82-109). London: Routledge.

Mackenzie, R., \& Cushion, C. (2013). Performance analysis in football: A critical review and implications for future research. Journal of Sports Sciences, 31(6), 639-676.

Memmert, D. (2002). Tactical performance components valuation: Test situations and concept-oriented expert ratings. (Unpublished dissertation, University of Heidelberg).

Memmert, D. (2010). Testing of tactical performance in youth elite soccer. Journal of Sports Science and Medicine, 9(2), 199-205.

Memmert, D., Lemmink, K., \& Sampaio, J. (2017). Current approaches to tactical performance analyses in soccer using position data. Sports Medicine, 47(1), 1-10.

Memmert, D., \& Roth, K. (2007). The effects of non-specific and specific concepts on tactical creativity in team ball sports. Journal of Sports Sciences, 25(12), 1423-1432. 
Ng, A., Jordan, M., \& Weiss, Y. (2002). On spectral clustering: Analysis and an algorithm. In S. Becker, S. Thrun \& K. Obermayer (Eds.), Advances in neural information processing systems 15 (pp. 849-856). Proceedings of the Neural Information Processing Systems Conference.

Ogris, G., Leser, R., Horsak, B., Kornfeind, P., Heller, M., \& Baca, A. (2012). Accuracy of the LPM tracking system considering dynamic position changes. Journal of Sports Sciences, 30(14), 1503-1511.

Oslin, J., Mitchell, S., \& Griffin, L. (1998). The game performance assessment instrument (GPAI): Development and preliminary validation. Journal of Teaching in Physical Education, 17(2), 231-243.

Otero-Saborido, F., \& Gonzalez-Jurado, J. (2015). Design and validation of a tool for the formative assessment of invasion games. Journal of Physical Education and Sport, 15(2), 254-263.

Owen, A., Twist, C., \& Ford, P. (2004). Small-sided games: The physiological and technical effect of altering pitch size and player numbers. Insight: The FA Coaches Association Journal, 2(7) 50-53.

Perl, J., Grunz, A., \& Memmert, D. (2013). Tactics analysis in soccer - An advanced approach. International Journal of Computer Science in Sport, 12(1), 33-44.

Pollard, R., \& Pollard. G. (2005). Long-term trends in home advantage in professional sports in North America and England (1876-2003). Journal of Sports Sciences, 23(4), 337-350.

Proteau, L., Marteniuk, R.G., \& Le' Vesque, L. (1992). A sensorimotor basis for motor learning: Evidence indicating specificity of practice. Quarterly Journal of Experimental Psychology, 44A, 557-575.

Reilly, T. (2005). An ergonomics model of soccer training process. Journal of Sports Sciences, 23(6), $561-572$.

Sampaio, J., \& Macas, V. (2012). Measuring tactical behaviour in football. International Journal of Sports Medicine, $33(5), 395-401$.

Sampaio, J., Lago, C., Goncalves, B., Macas, V., \& Leite, N. (2013). Effects of pacing, status and unbalance in timemotion variables, heart rate and tactical behaviour when playing 5-a-side football small-sided games. Journal of Science and Medicine in Sport, 17(2), 229-233.

Serra-Olivares, Clemente, F.M., \& Gonzàlez-Villora, S. (2016). Tactical expertise assessment in youth football using representative tasks. Springerplus, 5(1), 1301.

Silva, P., Duarte, R., Sampaio, J., Aguiar, P., Davids, K., Araujo, D., \& Garganta, J. (2014). Field dimension and skill level constrain team tactical behaviours in small-sided and conditioned games in football. Journal of Sports Sciences, 32(20), 1888-1896.

Stevens, T., de Ruiter, C., van Niel, C., van de Rhee, R., Beek, P., \& Savelsbergh, G. (2014). Measuring acceleration and deceleration in soccer-specific movements using a Local Position Measurement (LPM) system. International Journal of Sports Physiology and Performance, 9(3), 446-456.

Taylor, J., Mellalieu, S., \& James, N. (2005). A comparison of individual and unit tactical behaviour and team strategy in professional soccer. International Journal of Performance Analysis in Sport, 5(2), 87-101.

Ward, P., \& Williams, A.M. (2003). Perceptual and cognitive skill development in soccer: The multidimensional nature of expert performance. Journal of Sport and Exercise Psychology, 25(1), 93-111.

Williams, A.M., \& Hodges, N.J. (2005). Practice, instruction and skill acquisition in soccer: Challenging tradition. Journal of Sports Sciences, 23(6), 637-650.

Submitted: September 18, 2017

Accepted: March 22, 2018

Published Online First: March 25, 2019

Correspondence to:

Roland Leser, Ph.D.

Centre of Sport Science and University Sports,

University of Vienna,

Auf der Schmelz 6, A-1150 Vienna, Austria

Phone: 004364475042049

E-mail: roland.leser@univie.ac.at

\section{Acknowledgement}

This work was supported by the Austrian Research Promotion Agency (FFG) under Grant 841281. 